\title{
Numerical Analysis on Air Ingress Behavior in GTHTR300-Cogeneration System"
}

\author{
Tetsuaki TAKEDA $^{* *}$ Xing YAN $^{* *}$ and Kazuhiko KUNITOMI ${ }^{* *}$ \\ **Japan Atomic Energy Agency, \\ 4002 Narita-cho, Oarai-machi, Higashi-ibaraki-gun, Ibaraki 311-1393, Japan \\ E-mail: takeda.tetsuaki@jaea.go.jp
}

\begin{abstract}
The objective of this study is to clarify safety characteristics of a High Temperature Gas-Cooled Reactor (HTGR) for the pipe rupture accident. Japan Atomic Energy Agency (JAEA) has been developing the analytical code for the safety characteristics of the HTGR and carrying out design study of the gas turbine high temperature reactor of $300 \mathrm{MWe}$ nominal-capacity for hydrogen production, the GTHTR300C (Gas Turbine High Temperature Reactor 300 for Cogeneration). A numerical analysis of heat and mass transfer fluid flow with multi-component gas mixture has been performed to obtain the variation of the density of the gas mixture, and the onset time of natural circulation of air. From the results obtained in this analysis, it was found that the duration time of the air ingress by molecular diffusion would increase due to the existence of the recuperator in the GTHTR300C system.
\end{abstract}

Key words: High Temperature Gas Cooled Reactor, Numerical Analysis, Multi Component Gas, Natural Circulation, Molecular Diffusion

\section{Introduction}

High temperature gas-cooled reactor (HTGR) has currently strong interests of development worldwide. Besides its broad economical appeals resulting from unique high temperature capability, the reactor provides inherent and passive safety and aims at enhanced safety goal. Japan Atomic Energy Agency (JAEA) has successfully built and operated the $30 \mathrm{MWt}$ High Temperature Engineering Test Reactor (HTTR) and is now pursuing design and development of commercial systems such as the $300 \mathrm{MWe}$ gas turbine high temperature reactor GTHTR300 ${ }^{(1)}$. In order to deploy a commercialized high temperature gas-cooled reactor cogeneration system in around 2030, JAEA is also carrying out the research and development of the reactor technology, of the connection technology and of the Iodine-Sulfur (I/S) thermo-chemical hydrogen production process technology using the HTTR. JAEA is now performing development and validation of the analytical codes for the design and safety assessment aiming at the development of HTGR that has a high inherent safety and economy. These analytical codes will be verified by using the experimental data of the HTTR and of the out-of-pile test facilities. As for the experiment, we have been performing the HTTR safety demonstration test such as a reactivity insertion (control rod withdrawal) test, a coolant flow reduction test, and a loss of forced cooling (gas circulators trip) test ${ }^{(2)}$.

On the other hand, we are carrying out design study of the GTHTR300C (Gas Turbine High Temperature Reactor 300 for Cogeneration). A safety goal for the HTGR of recent designs considers a primary pipe rupture as design basis accident. A depressurization accident by the primary pipe rupture is one of the design-basis accidents of the

*Received 17 Oct., 2006 (No. 06-0154) [DOI: 10.1299/.jpes.1.24] 
GTHTR300C. When the double coaxial duct connecting between a reactor core and an intermediate heat exchanger (IHX) module breaks, air is expected to enter the reactor core from the breach and oxidize in-core graphite structures. In the primary pipe rupture accident, we still have to consider not only air ingress into the core through the breached pipe but also a potential fuel failure by graphite oxidation. Air ingress phenomena in HTGR is known to follow two sequential phases, starting with molecular diffusion and very weak natural circulation of gas mixture and, natural circulation of air develop suddenly as once sufficient buoyancy is established ${ }^{(3)}$.

This study is to investigate the air ingress phenomena and to develop the passive safe technology for the prevention of air ingress and of graphite corrosion. In order to clarify safety characteristics of the GTHTR300C in the pipe rupture accident, we have performed a preliminary analysis of air ingress. The present paper describes an overview of the results of the numerical analysis of the air ingress during the primary pipe rupture accident of the GTHTR300C. This paper also describes the effectiveness of the proposed method for the prevention of air ingress during the accident.

\section{Design concept of GTHTR300C}

\section{GTHTR300C System Outline}

Figure 1 shows the system layout of the GTHTR300C. The power rating of the gas turbine and hydrogen system has been set by raising the reactor outlet temperature $100^{\circ} \mathrm{C}$, and by leaving the gas turbine inlet and outlet temperature as same. The helically coiled $\mathrm{He} / \mathrm{He} \mathrm{IHX}$ is installed between the reactor pressure vessel (RPV) and the gas turbine system. Even though the thermal capacity for the gas turbine system decreases to 430MWt from 600MWt for the GTHTR300C, no major design change of the primary components has been made except the addition of the IHX. A comparison of major design specifications between GTHTR300 and GTHTR300C is shown in Table 1.

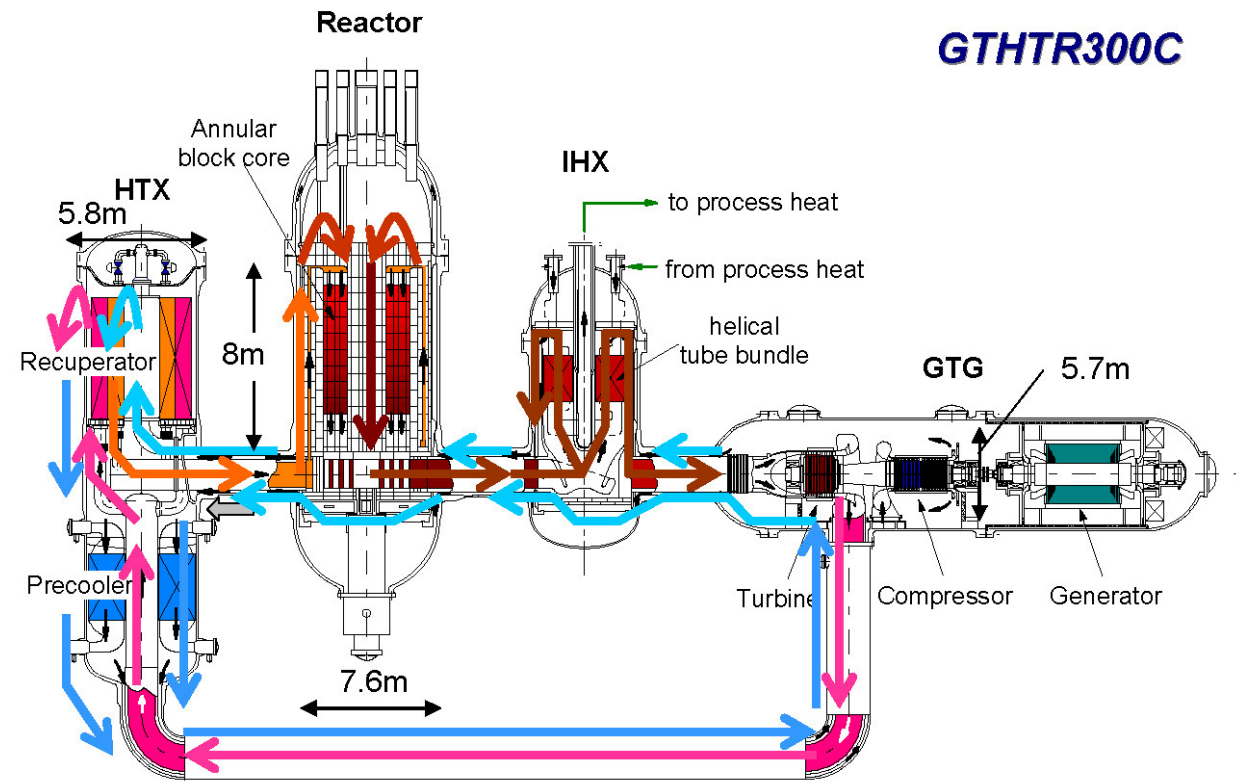

Fig. 1 System layout of GTHTR300C

The reactor power is $600 \mathrm{MWt}$ and its outlet coolant gas temperature is $950^{\circ} \mathrm{C}$. The thermal power for the process heat including hydrogen production is $170 \mathrm{MWt}$. The 
nuclear heat is transferred through the IHX to the secondary cooling system and then through a compact heat exchanger to the hydrogen production system. The reactor outlet helium of $950^{\circ} \mathrm{C}$ enters the shell side of the IHX and exits it at $850^{\circ} \mathrm{C}$. The helium of $850^{\circ} \mathrm{C}$ from the IHX drives the turbine and goes to the recuperator, precooler and compressor. The outlet helium of $135^{\circ} \mathrm{C}$ from the compressor is guided to cool the RPV allowing for the vessel made of the pressure vessel steel used in existing LWR. The GTHTR300C system generates electricity of approximately 200MWe.

In case of malfunction of the hydrogen production system, the reactor outlet temperature will be reduced from $950^{\circ} \mathrm{C}$ to $850^{\circ} \mathrm{C}$ and the reactor continues to produce the same amount of electricity. On the other hand, in case of loss of an electrical load of the grid, the reactor power will be reduced to the power level necessary for driving the gas turbine and the reactor to provide continuously the heat to the hydrogen production system.

Table 1 Major design specification of GTHTR300C and 300

\begin{tabular}{|l|c|c|}
\hline Items & GTHTR300C & GTHTR300 \\
\hline Reactor power & $600 \mathrm{MWt}$ & $600 \mathrm{MWt}$ \\
\hline Hydrogen/Electricity & $170 / 430 \mathrm{MWt}$ & $0 / 600 \mathrm{MWt}$ \\
\hline Outlet gas temperature & $950^{\circ} \mathrm{C}$ & $850^{\circ} \mathrm{C}$ \\
\hline Inlet gas temperature & $594^{\circ} \mathrm{C}$ & $587^{\circ} \mathrm{C}$ \\
\hline Primary flow rate & $324 \mathrm{~kg} / \mathrm{s}$ & $439 \mathrm{~kg} / \mathrm{s}$ \\
\hline Primary pressure & $5.1 \mathrm{MPa}$ & $6.9 \mathrm{MPa}$ \\
\hline Operational cycle & $1.5 \mathrm{year}$ & $2 \mathrm{year}$ \\
\hline Burnup rate & $120 \mathrm{GWd} / \mathrm{t}$ & $120 \mathrm{GWd} / \mathrm{t}$ \\
\hline Electricity generation & $202 \mathrm{MWe}$ & $274 \mathrm{MWe}$ \\
\hline Hydrogen production & $1.9 \sim 2.4 \mathrm{t} / \mathrm{h}$ & --- \\
\hline Efficiency of electric generation & $45.7 \%$ & $45 \%$ \\
\hline Efficiency of hydrogen production & $45 \sim 55 \%$ & --- \\
\hline
\end{tabular}

\section{Numerical analysis of air ingress phenomena}

\section{Outline of numerical code}

FLOWGR provides a numerical method for analyzing the transient thermal hydraulic behavior by solving the one-dimensional basic equations for continuity, momentum conservation, energy conservation of the gas mixture, and the mass conservation of each gas species ${ }^{(4)}$. The main features of FLOWGR are explained as follows. FLOWGR treats the gas mixture consisting of arbitrary components and takes into account the graphite oxidation and $\mathrm{CO}$ combustion reactions. The source and sink terms in the mass conservation equations resulting from these chemical reactions are expressed by the temperature dependent Arrhenius formula having rate constants which are specified by the user. The reactor system to be analyzed by FLOWGR is modeled as a network of one dimensional stream-tubes which represent components of the system such as a piping, plenum and reactor core. Each stream-tube is further divided into fluid volumes (control volumes or cells). There are three types of tube-ends: a normal, break and closed end. The normal end connects with adjacent stream-tubes, the closed end has no adjacent stream-tube and the break end represents the breach connected to the open air.

\section{Basic equation}

The basic equations (mass-based formulation) are as follows.

The equation of continuity for the gas mixture: 


$$
\frac{\partial \rho}{\partial t}+\frac{\partial(\rho u)}{\partial x}=\sum_{i=1}^{n} Q_{i}
$$

The equation of mass conservation for each gas species:

$$
\begin{aligned}
& \frac{\partial\left(\rho \omega_{i}\right)}{\partial t}+\frac{\partial\left(\rho u \omega_{i}\right)}{\partial x}=\frac{\partial}{\partial x}\left(\rho D_{i-m} \frac{\partial \omega_{i}}{\partial x}\right)+Q \\
& \text { For i=1 to n-1, and } \omega_{n}=1-\sum_{k=1}^{n-1} \omega_{k} .
\end{aligned}
$$

The equation of energy conservation:

$$
\frac{\partial\left(\rho c_{p} T\right)}{\partial}+\frac{\partial\left(\rho u c_{p} T\right)}{\partial x}=\frac{\partial}{\partial x}\left(\lambda \frac{\partial T}{\partial x}\right)+\alpha \frac{L_{h}}{A_{e}}\left(T_{w}-T\right)
$$

The equation of momentum conservation:

$$
\frac{\partial(\rho u)}{\partial}+\frac{\partial\left(\rho u^{2}\right)}{\partial x}=-\frac{\partial p}{\partial x}-\rho g \cos \theta-\frac{1}{2} \rho u \mid u\left(\frac{f}{D_{e}}\right)
$$

The equation of state for the gas:

$$
p M_{m}=\rho R T \text { or } p=C R T \text {. }
$$

Here, the friction (f) and the heat transfer coefficient $(\alpha)$ corresponding to the fully developed laminar flow are used ${ }^{(5)}$. The viscosity $(\mu)$ and thermal conductivity $(\lambda)$ of each gas species and the gas mixture is obtained using the Wilke method and by the Eucken correlation ${ }^{(6)}$, respectively.

The other set of the basic equations (molecule-based formulation) includes the equations of continuity (Eq.(6)) and of number of molecules conservation for each gas species (Eq.(7)) instead of Eq.(1) and Eq.(2).

The equation of continuity for the gas mixture:

$$
\frac{\partial C}{\partial t}+\frac{\partial(C u)}{\partial x}=\sum_{i=1}^{n}\left(Q_{i} / M_{i}\right)
$$

The equation of number of molecules conservation for each gas species:

$$
\frac{\partial\left(C X_{i}\right)}{\partial}+\frac{\partial\left(C u X_{i}\right)}{\partial x}=\frac{\partial}{\partial x}\left(C D_{i-m} \frac{\partial X_{i}}{\partial x}\right)+\frac{Q_{i}}{M_{i}}
$$

For $\mathrm{i}=1$ to $\mathrm{n}-1$, and $X_{n}=1-\sum_{k=1}^{n-1} X_{k}$.

Where $X_{i}=$ mole fraction for the component gas $i, M_{i}=$ molecular weight. In this set of equations, the conservation equation of momentum (Eq.(4)) and the equation of state for the gas (Eq.(5)) are used. However, the equation of energy conservation (Eq.(3)) is omitted based on the assumption that the gas temperature is equal to the wall temperature.

The diffusion coefficients $\mathrm{D}_{\mathrm{i}-\mathrm{m}}$ for the multi-component gas system are obtained from the diffusion coefficients for the binary gas system and the mole fractions of each gas species.

$$
D_{i-m}=\frac{1-X_{i}}{\sum_{j=1}^{n} \frac{X_{j}}{D_{i-j}}}
$$

This coefficient is called the effective diffusion coefficient in the multi-component gas mixture, which is provided by references ${ }^{(7-9)}$.

In the present analysis, the graphite oxidation reaction $\left(\mathrm{C}-\mathrm{O}_{2}\right.$ reaction) and the carbon monoxide combustion $\left(\mathrm{CO}-\mathrm{O}_{2}\right.$ reaction) are taken into account. The dissipation or generation terms $\mathrm{Q}_{\mathrm{i}}$ of the mass conservation equations for $\mathrm{O}_{2}, \mathrm{CO}$ and $\mathrm{CO}_{2}$ are written as: 


$$
Q_{i}=Q_{i}^{(1)}+Q_{i}^{(2)},
$$

Where $Q_{i}^{(1)}$ is the term for the graphite oxidation reaction and $Q_{i}^{(2)}$ the one for the CO combustion. Using the arrhenius formula, these terms are

$$
\begin{aligned}
& Q_{i}^{(1)}=K_{i}^{(1)} \exp \left(-\frac{E_{1}}{R T}\right), \\
& Q_{i}^{(2)}=K_{i}^{(2)} \exp \left(-\frac{E_{2}}{R T}\right) .
\end{aligned}
$$

Where $K_{i}^{(1)}$ and $K_{i}^{(2)}$ are constants, $\mathrm{E}_{1}$ and $\mathrm{E}_{2}$ the activation energies. Details of these constants and activation energies are explained in reference ${ }^{(10)}$.

In the present analysis, the concept of an effective diffusion coefficient ${ }^{(11)}$ is introduced to take into account of the transportation of air by the three-dimensional natural convection of the gas mixture. For example, it seems to be probable that the three-dimensional natural convection takes place in the top cover, lower plenum. Then, we roughly estimated the amount of air transported by the natural convection. The calculated results using the effective diffusion coefficient agree well with the experimental one ${ }^{(11)}$.

\section{Numerical methods}

The numerical methods are based on replacing the system of differential equations with a system of finite-difference equations fully implicit in time except the convection term for the momentum equation, which is treated explicitly. These results in a set of discretized nonlinear equations are solved by iteration procedure. In each iteration time, the implicit terms are formulated to be linear in the dependent variables at new time.

The finite-difference equations used in FLOWGR can be obtained by integrating the conservation equations over a fixed fluid volume. The scalar properties (pressure, temperature, etc.) of the flow are defined at the volume centers, while vector quantity (velocity) is defined at the junctions. The equations of continuity and mass conservation (Eqs.(1) and (2)), and the equation of energy conservation (Eq.(3)) for the mass-based formulation as well as the equations (Eqs.(6) and (7)) for the molar-based formulation are integrated with respect to the spatial variable $x$ from the junction at $x_{j}$ to the junction at $x_{j+1}$. The equation of momentum conservation (Eq.(4)) is integrated with respect to the spatial variable from the volume center at $x_{j+1 / 2}$ to the adjacent volume center at $x_{j+3 / 2}$. In this integration loss of pressure is taken into account at the volume boundary with abrupt area change. The fluxes due to convection and diffusion, which appear in the integrated equations, are approximated using the hybrid difference scheme ${ }^{(12,13)}$.

The finite-difference equations can be solved under the initial and boundary conditions. The initial conditions for the temperature, pressure and mole fractions for each component gas are specified at the volume centers and those for velocities at the junctions. In order to analyze the phenomenon just after the depressurization stage, it is assumed that the gas velocities are zero for the initial condition. As for the boundary conditions, the pressure, temperature, mole fractions of each gas species are specified at the end of the stream-tube, which has the break end. The wall temperature of the stream tubes is also specified for each control volume as a function of time.

\section{Results of numerical analysis}

Figure 2 shows the network model of the GTHTR300C system. The mesh status and the initial condition of the temperature are shown in Table 2. The location of the break point is assumed to the $0.7 \mathrm{~m}$ from the pressure vessel between the reactor and the IHX module. The initial condition of the wall temperature at the pipe rupture accident was given by another result of reactor core temperature analysis ${ }^{(1)}$. This is defined as the analytical condition A (Case A). Figure 3 shows an example of the analytical results of 
temperature change in the reactor during the accident. The analytical condition B (Case B) is the case of setting a helium canister in the top space of the recuperator.

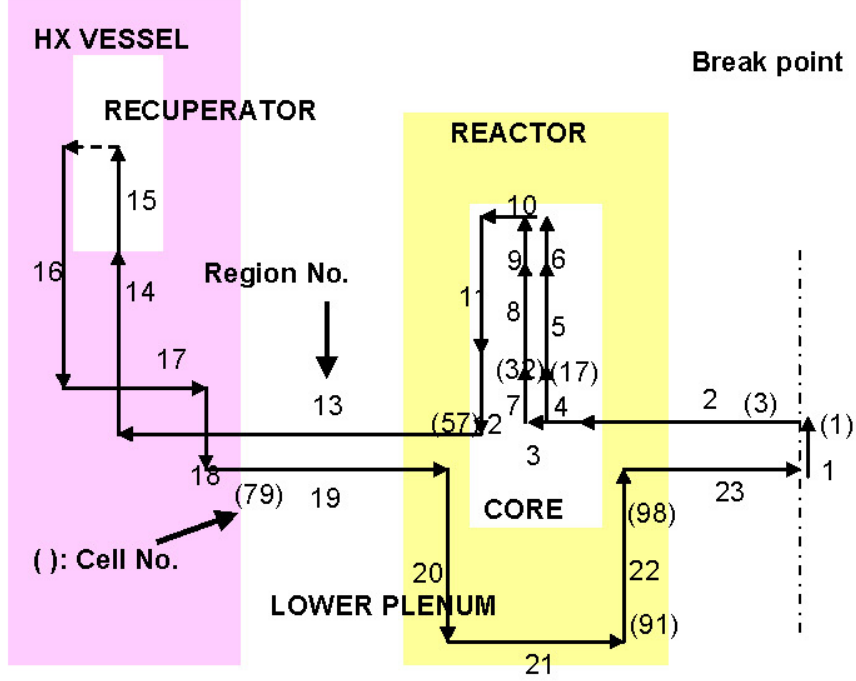

Fig. 2 Network model

Table 2 Mesh status and initial condition of temperature

\begin{tabular}{|l|l|c|r|r|r|}
\hline R- & \multicolumn{1}{|c|}{ Part } & Cell & $\mathrm{T}$ (bot) & $\mathrm{T}$ (mid) & $\mathrm{T}$ (top) \\
\hline 1 & Vertical part & 2 & $150^{\circ} \mathrm{C}$ & $150^{\circ} \mathrm{C}$ & $150^{\circ} \mathrm{C}$ \\
\hline 2 & Inlet duct & 4 & 150 & 200 & 250 \\
\hline 3 & Hot plenum & 5 & 700 & 700 & 700 \\
\hline 4 & Center core (bot) & 5 & 700 & 850 & 950 \\
\hline 5 & Center core (mid) & 5 & 950 & 1600 & 1100 \\
\hline 6 & Center core (top) & 5 & 1100 & 1100 & 1100 \\
\hline 7 & Peripheral core (bot) & 5 & 700 & 800 & 900 \\
\hline 8 & Peripheral core (mid) & 5 & 900 & 1500 & 1500 \\
\hline 9 & Peripheral core (top) & 5 & 1050 & 1050 & 1050 \\
\hline 10 & Top cover & 5 & 1050 & 1050 & 1050 \\
\hline 11 & Outside core (top) & 5 & 1050 & 1000 & 700 \\
\hline 12 & Outside core (bot) & 5 & 700 & 450 & 250 \\
\hline 13 & Inner duct to HX & 4 & 250 & 200 & 150 \\
\hline 14 & Vertical path to HX & 3 & 150 & 150 & 150 \\
\hline 15 & Recuperator inside & 3 & 150 & 150 & 150 \\
\hline 16 & Recuperator outside & 4 & 150 & 150 & 150 \\
\hline 17 & Horizontal path & 4 & 150 & 150 & 150 \\
\hline 18 & Vertical path to HX & 4 & 150 & 150 & 150 \\
\hline 19 & Outer duct to plenum & 4 & 150 & 200 & 250 \\
\hline 20 & Cold plenum-1 & 4 & 250 & 250 & 250 \\
\hline 21 & Cold plenum-2 & 4 & 300 & 300 & 300 \\
\hline 22 & Cold plenum-3 & 4 & 250 & 250 & 250 \\
\hline 23 & Cold plenum-4 & 4 & 250 & 200 & 150 \\
\hline & & & & & \\
\hline
\end{tabular}

Figure 4 to 6 show the time variation of the density of the gas mixture, the mole fraction of Oxygen, and Carbon dioxide in the condition A, respectively. Air is expected 
to enter the reactor core from the inner pipe because the buoyancy will produce by the density difference between the high temperature and low temperature passage in the reactor. However, the steady natural circulation of air will not occur because the density difference becomes so small with the passage of time.

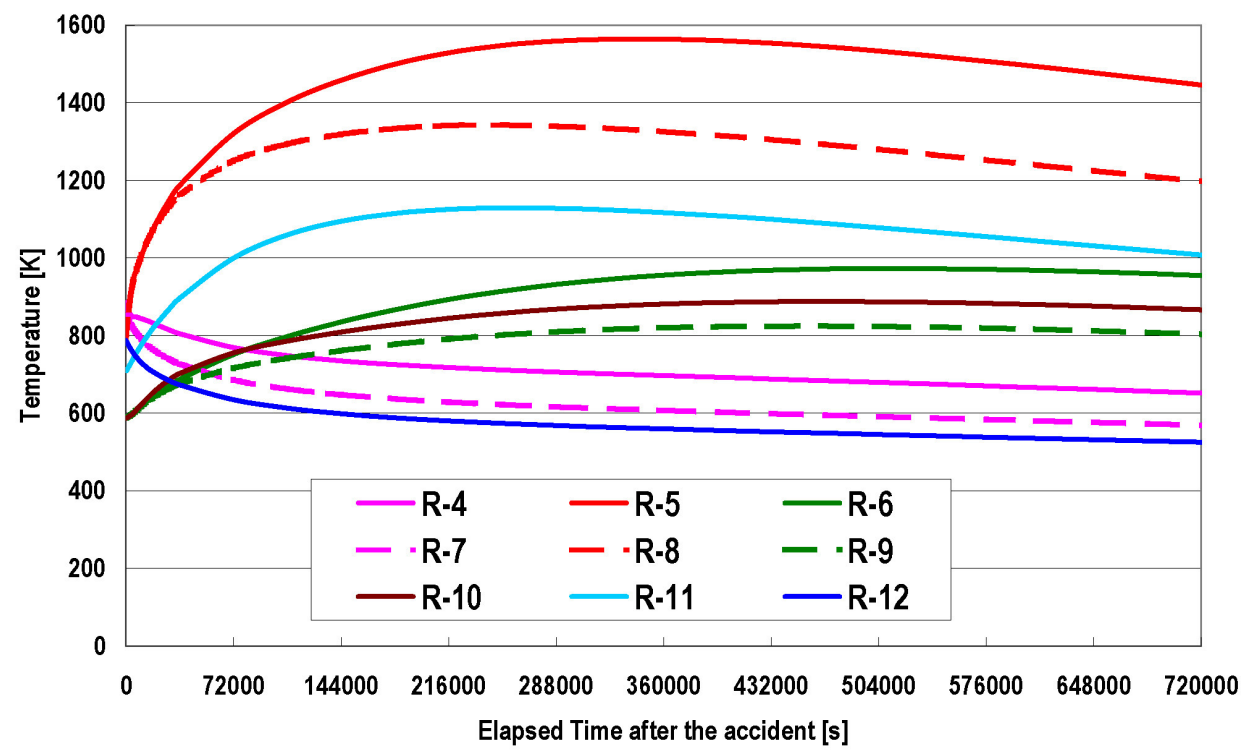

Fig. 3 Temperature changes in the core after the accident

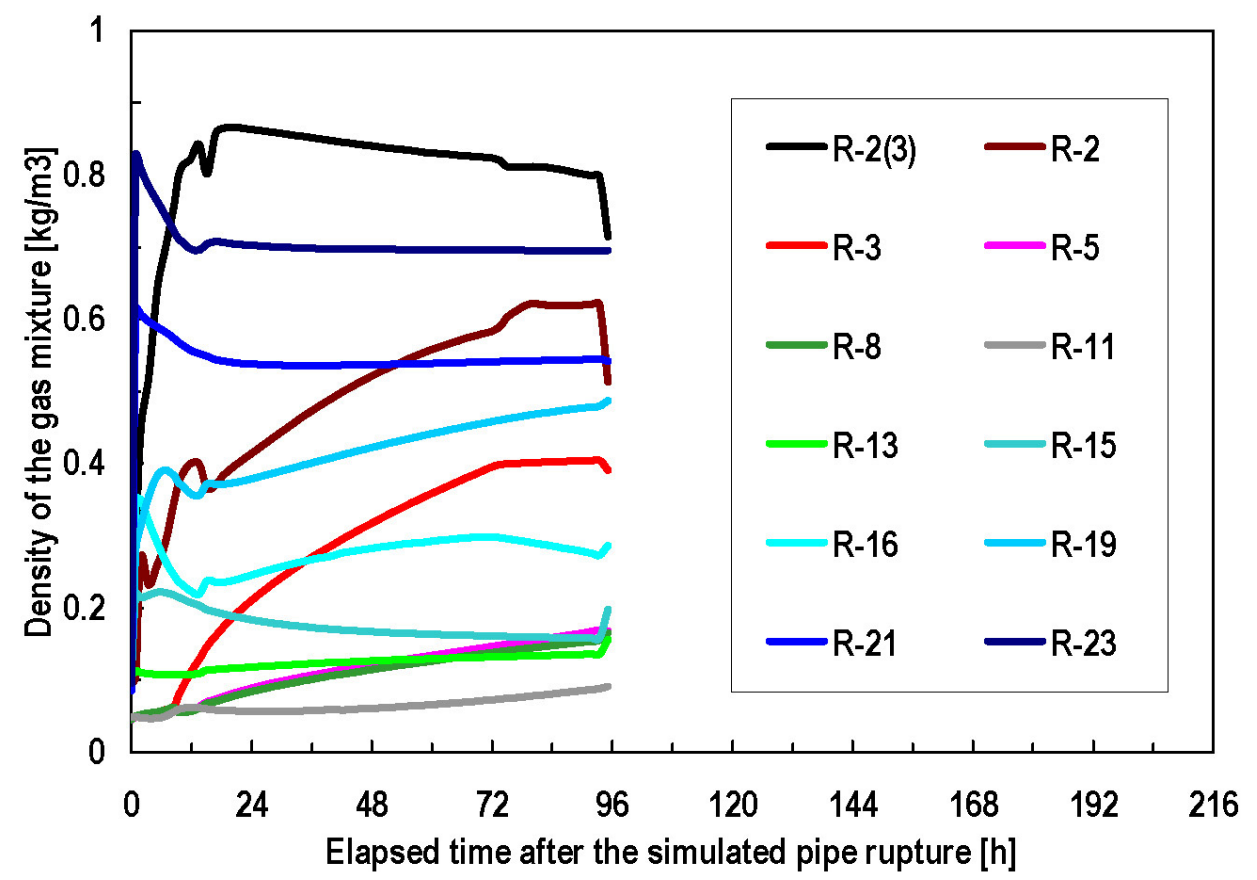

Fig. 4 Density changes of the gas mixture (Case A)

On the other hand, air enters the lower plenum from the breached outer pipe just after the pipe rupture because the plenum is located below the breached pipe. The exchange flow of air and helium will occur in the breached portion. Then, the lower plenum will be filled with air. 


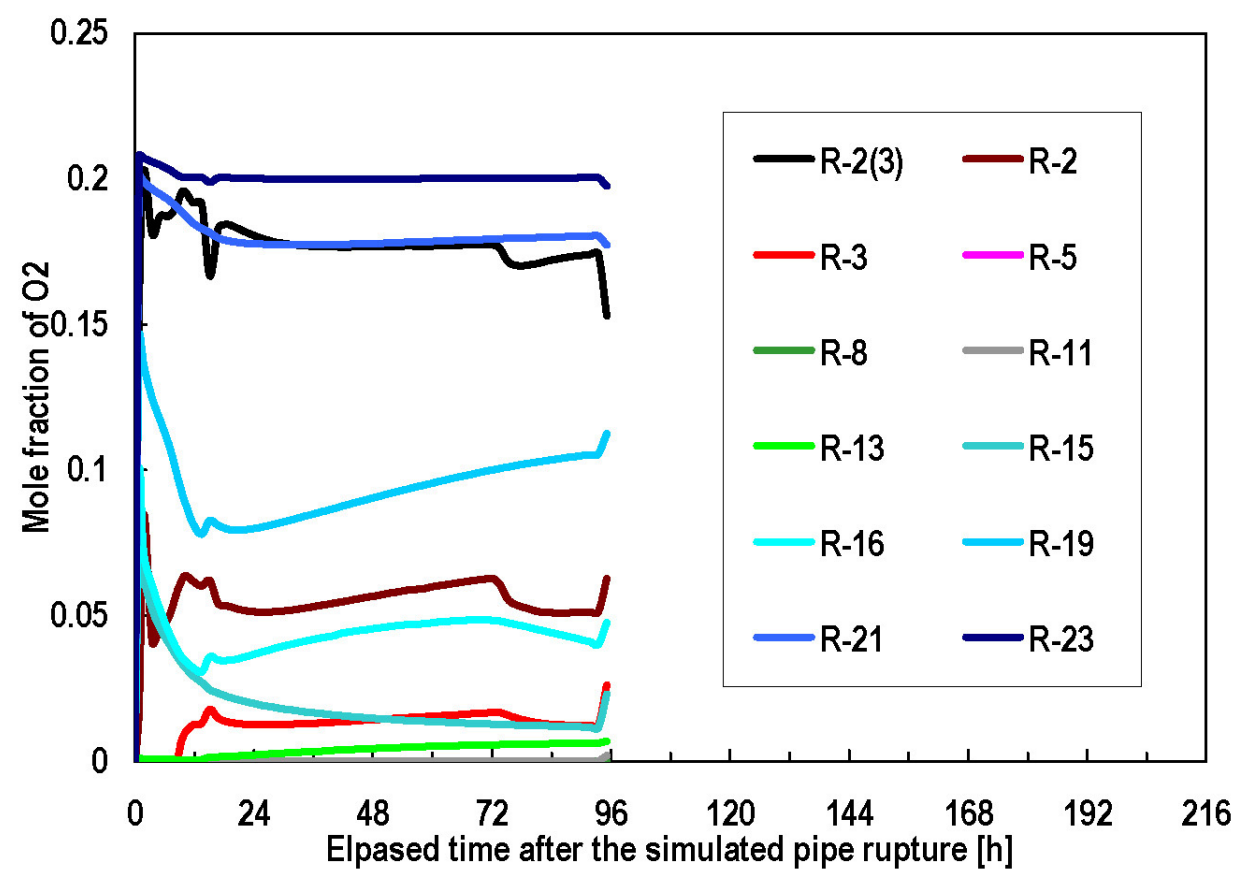

Fig. 5 Mole fraction changes of Oxygen (Case A)

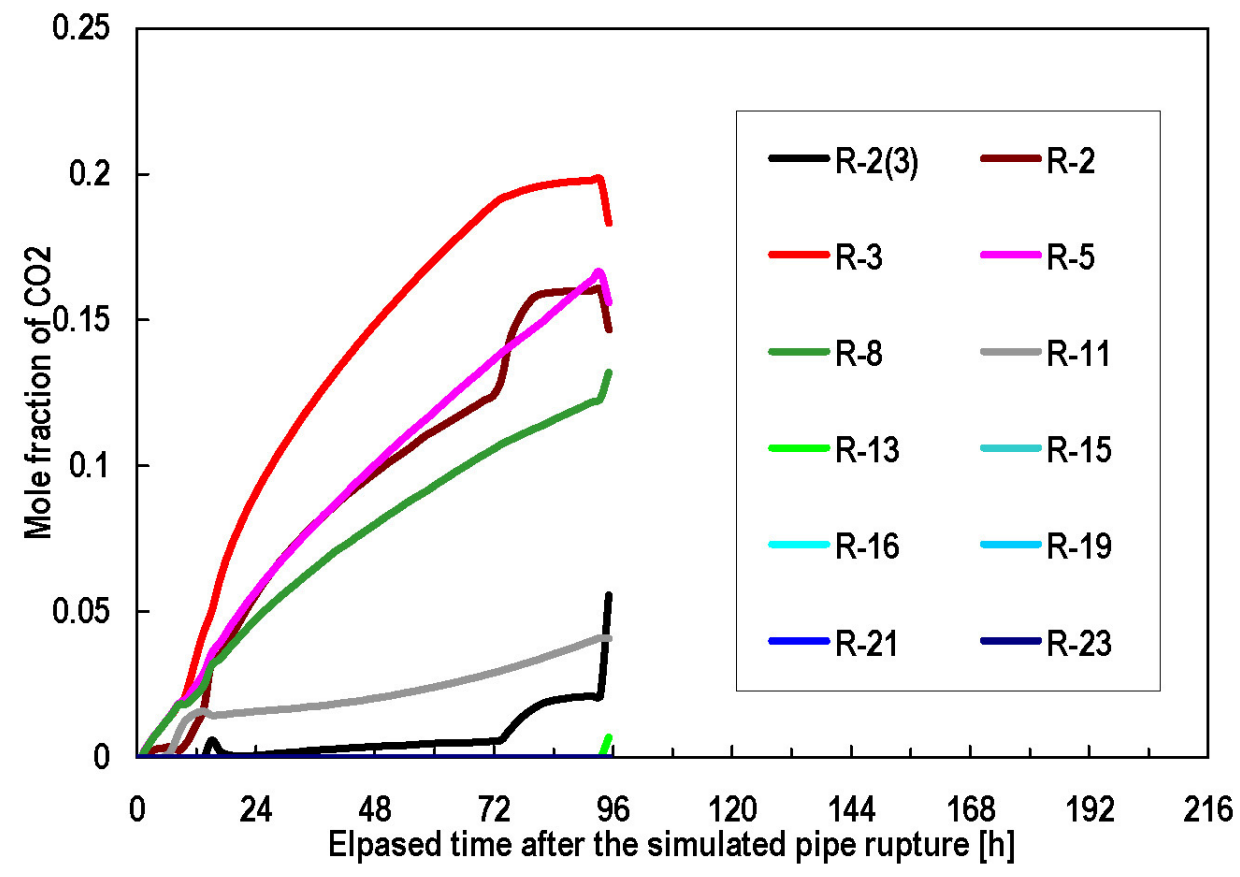

Fig. 6 Mole fraction changes of Carbon dioxide (Case A)

If air exists in the inside and outside of the reactor during the accident, the natural circulation of air through the reactor core will occur continuously. However, when the double coaxial pipe connecting between the reactor and the IHX module ruptures, the lighter helium exists above the breached pipe and the heavier air exists below the pipe. Then, the stable stratification will form in a confinement of the GTHTR300C. Therefore, air enters the reactor by mainly molecular diffusion and by the very weak natural circulation of air. In this case, the natural circulation of air is generated at 4 days after the pipe 
rupture. According to the experimental results using the apparatus which simulated reactor core, the first stage has kept more than 5 days ${ }^{(4)}$. So, the analytical result regarding the duration time of the first stage is too conservative one. Air ingress phenomena in the GTHTR300C were same as the previous experiment and analysis.

According to the previous research ${ }^{(4)}$, in the case of the average temperature of the graphite pipe exceeds $750^{\circ} \mathrm{C}$, the temperature of the graphite pipe increases after the second stage of the accident due to the graphite oxidation reaction. On the other hands, in the case of the temperature lower than $700^{\circ} \mathrm{C}$, the temperature of the graphite pipe decreases after the onset of the ordinary natural circulation of air. This is because the natural circulation of cold air cools the simulated core and the reaction rate of the graphite oxidation becomes slow. Thus, it is supposed that the limitation value of temperature rise after the second stage exists between $700^{\circ} \mathrm{C}$ and $750^{\circ} \mathrm{C}$ in the graphite temperature.

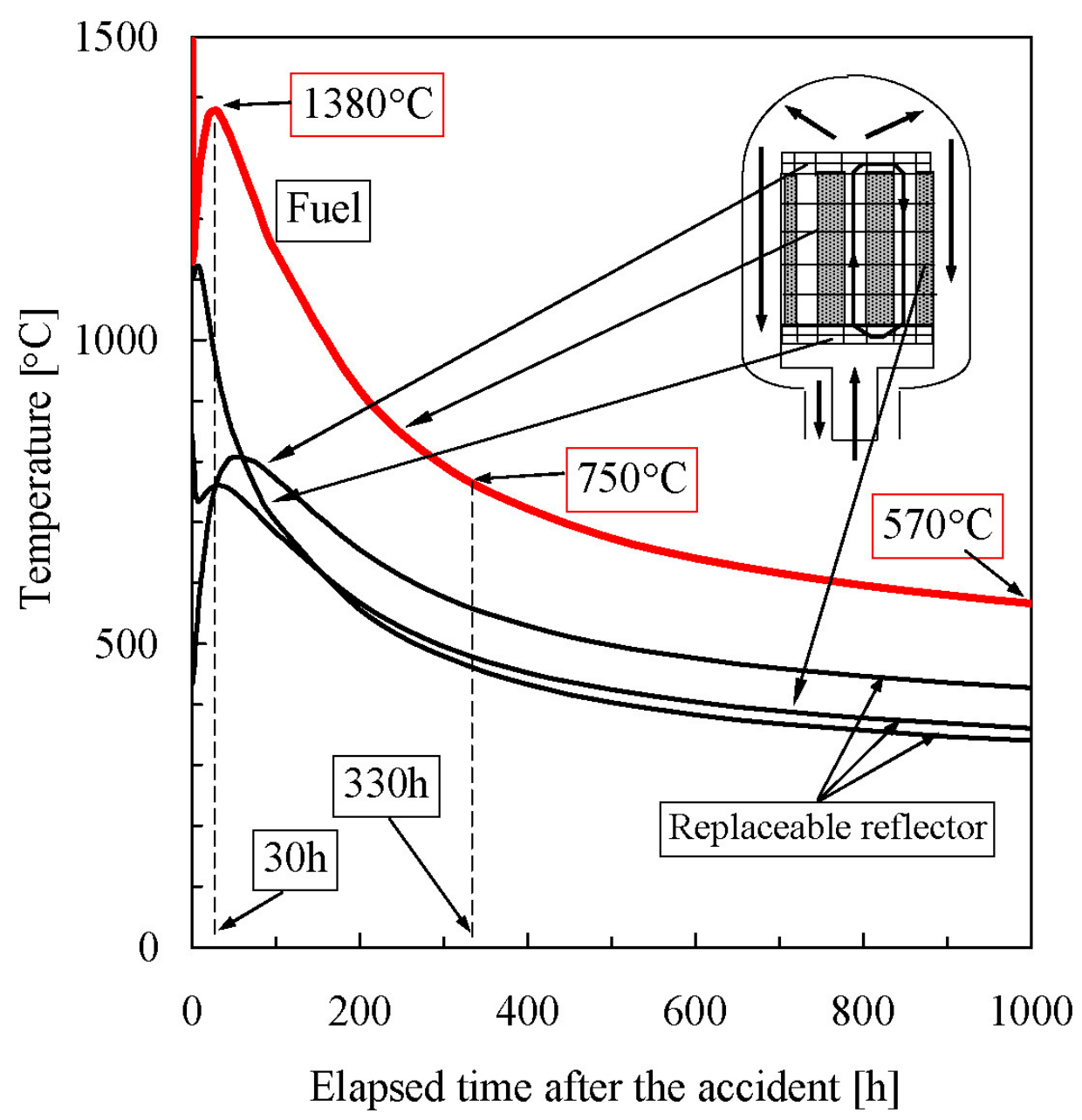

Fig. 7 Temperature changes in the fuel and replaceable reflector blocks during the accident

Figure 7 shows the analytical results of the maximum temperature in the fuel block, the upper and lower replaceable reflector block during the accident at the end of core life of the HTTR ${ }^{(14,15)}$. The maximum temperature in the fuel blocks decreases rapidly after the reactor scram and then increases slightly due to decay heat. The peak fuel temperature is $1380^{\circ} \mathrm{C}$ at about 30 hours after the accident was happened. The temperature of the fuel block is lower than $750^{\circ} \mathrm{C}$ at 330 hours and that of the replaceable reflectors are lower than $750^{\circ} \mathrm{C}$ at about 50 hours after the accident were started. 
The objective of the preliminary analysis is to investigate the effect to the onset time of natural circulation by existing of the recuperator module. In this analysis, we adopt 98 cells for the analytical condition A and 104 cells for the condition B in order to reduce the calculation time. According to the previous analysis, we found the onset time of natural circulation by the analysis is shorter than that by the experiment, if the number of cell is few. Therefore, though the duration time of the first stage which means air ingress by mainly molecular diffusion becomes short, it is conservative assumption.

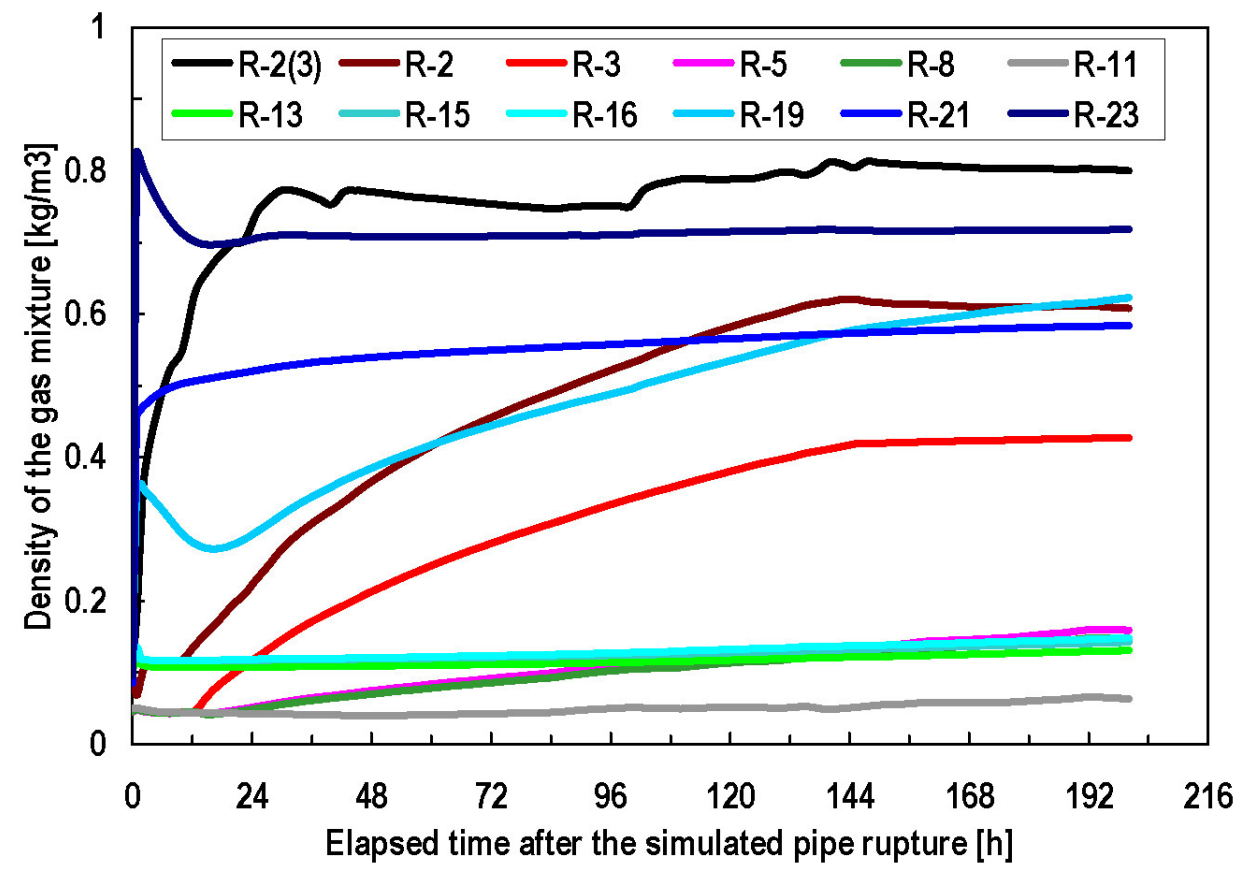

Fig. 8 Density changes of gas mixture (Case B)

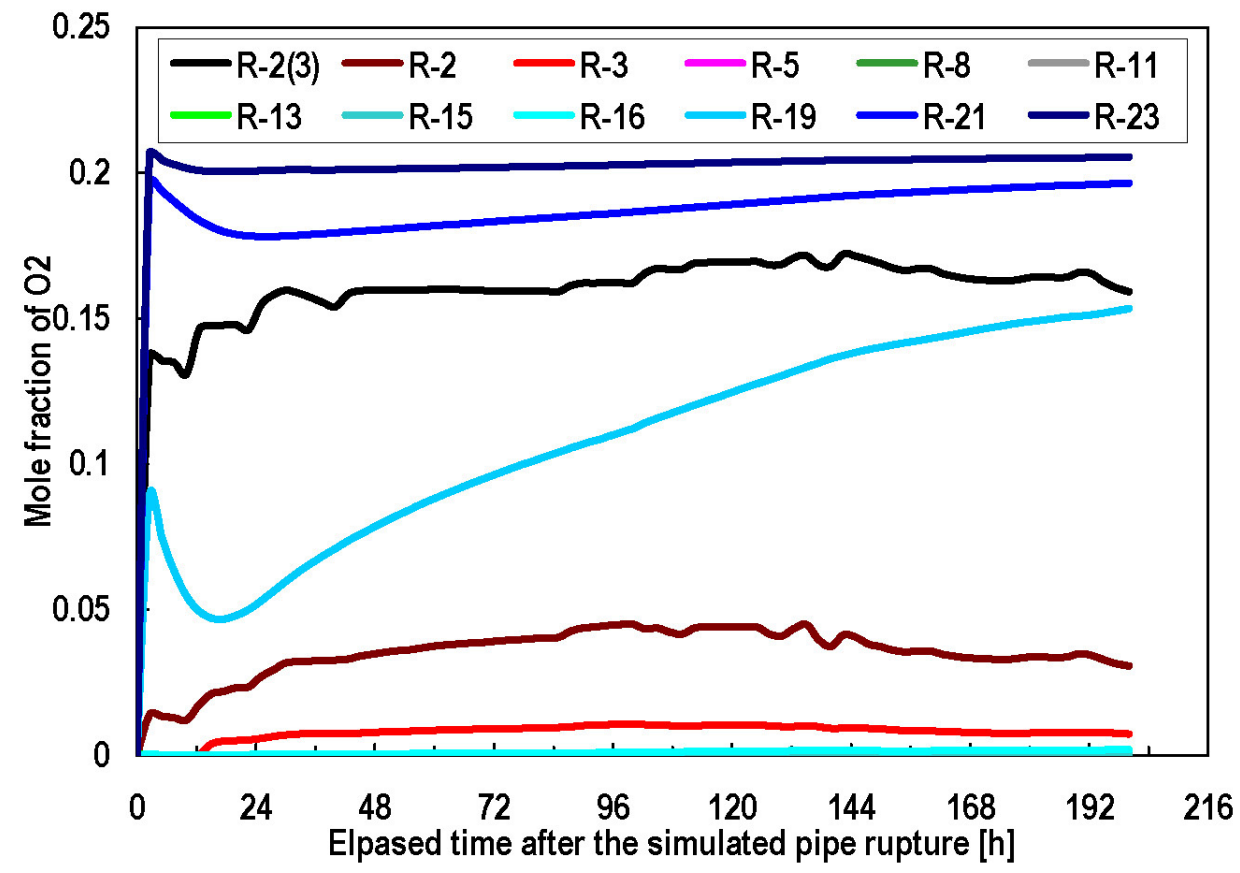

Fig. 9 Mole fraction changes of Oxygen (case B) 
We discussed the effectiveness of the top space of the recuperator filled with helium gas for air ingress behavior. In the analytical condition B, a 6 times more space is given in the top of the recuperator, between the region number 15 and 16 in Fig.2. The large amount of volume was given there, because we want to see clearly the effect of this design change. Figure 8 to 10 show the variation of the mixture gas density, of the mole fraction of Oxygen, and of the mole fraction of Carbon dioxide in the analytical condition B, respectively. In this case, the natural circulation of air did not occur during 200 hours after the pipe rupture. The first stage has kept more than 100 hours as compared with the analytical condition A. The onset time of natural circulation becomes longer because helium gas of the top space of the recuperator do not find a way out from the reactor except by molecular diffusion. Therefore, this space filled with helium becomes the flow resistance of the natural circulation flow of air. From these results, if the canister filled with helium can be equipped at the top space of the recuperator and continuously released a small amount of helium to the reactor, it is possible to prevent air ingress by this method.

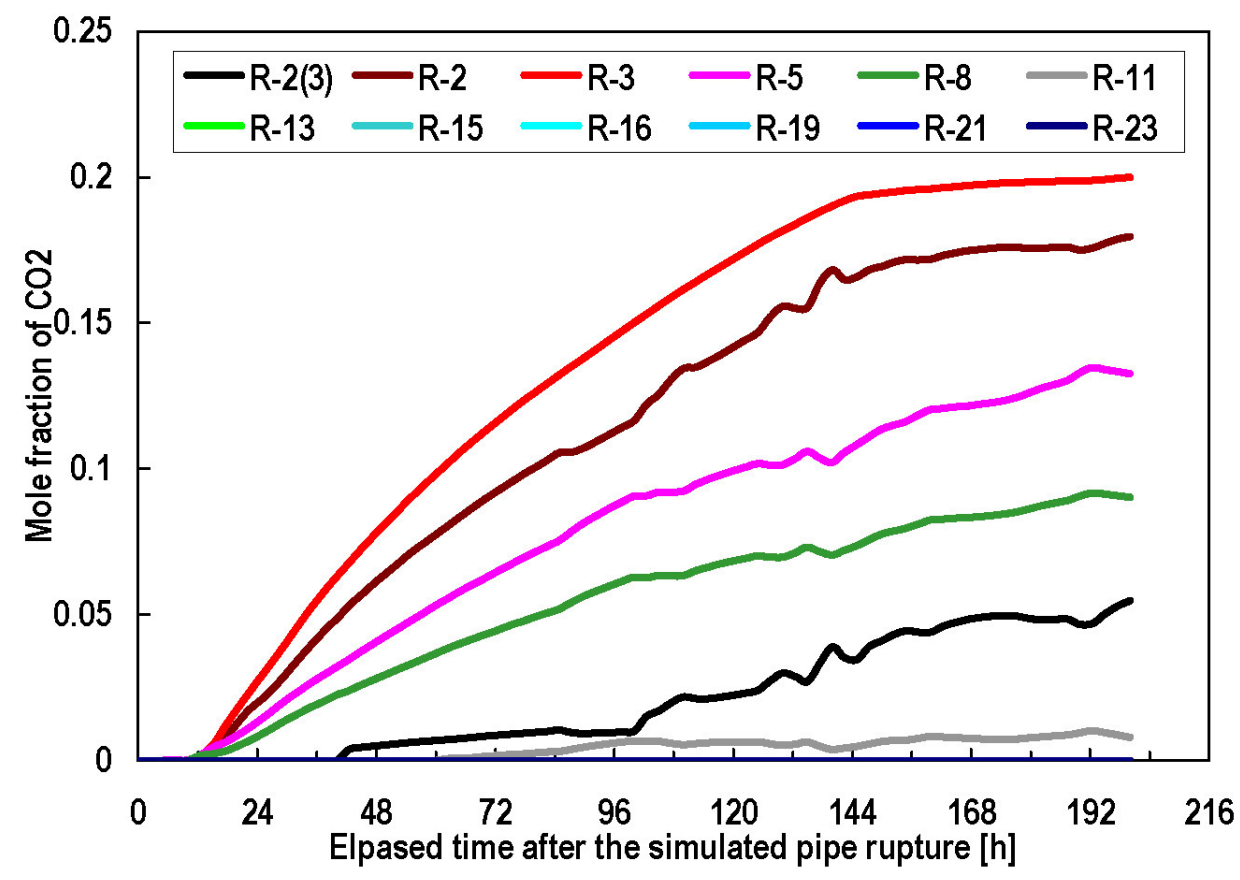

Fig. 10 Mole fraction changes of Carbon dioxide (Case B)

\section{Conclusions}

The preliminary calculation has been carried out to investigate the air ingress phenomena and to develop the passive safety technology for the prevention of air ingress and of graphite corrosion. The following conclusions are obtained from the present analysis.

From the results obtained in this analysis, it was found that the duration time of the air ingress by molecular diffusion would increase due to the existence of the recuperator in the GTHTR300C.

There are two stages in the primary-pipe rupture accident of the GTHTR300C. In the first stage of the accident, the molecular diffusion and the natural circulation of the gas mixture having the very slow velocity limit the air ingress. In the second stage of the accident, the ordinary natural circulation of air throughout the reactor limits the air ingress. 
In the passive safety technology development, if the canister filled with helium gas is equipped at the top space of the recuperator and only a small amount of helium gas is continuously released to the reactor, it is possible to prevent air ingress.

\section{References}

(1) Yan, X. L., et al., GTHTR300 design and development, Nuclear Engineering and Design, Vol.222 (2003), pp.247-262.

(2) Nakagawa, S., et al., Safety demonstration tests using high temperature engineering test reactor, Nuclear Engineering and Design, Vol. 233 (2004), pp.301-308.

(3) Takeda, T. and Hishida, M., Study on the passive safe technology for the prevention of air ingress during the primary-pipe rupture accident of HTGR, Nuclear Engineering and Design, Vol.200 (2000), pp.251-259.

(4) Takeda, T., Research and development on prevention of air ingress during the primary-pipe rupture accident of HTTR, Nuclear Engineering and Design, Vol.233 (2004), pp.197-209.

(5) Shah, R. K. and London, A. L., Advances in Heat Transfer: Laminar Flow Forced Convection in Ducts, (1978), p.78, Academic Press.

(6) Reid, R. C., Prausnitz, J. M., and Sherwood, T. K., The Properties of Gases and Liquids 3rd Edn., (1977), pp.37-40, 226, 410-414, 470-474, 548-565, McGraw-Hill.

(7) Wilke, C. R., Diffusional properties of multicomponent gases, Chem. Eng. Prog., Vol. 46 (1950), pp.95-104.

(8) Fairbanks, D. F. and Wilke, C. R., Diffusion coefficients in multicomonent gas mixture, Ind. Eng. Chem., Vol. 42 (1950), pp.471-475.

(9) Walker, R. E., deHaas, N., and Westenberg, A. A., Measurements of multicomponent diffusion coefficients for the CO2-He-N2 system using the point source technique, $J$. Chem. Phys., Vol. 32 (1960), pp.1314-1316.

(10) Takeda, T. and Hishida, M., Studies on molecular diffusion and natural convection in a multicomponent gas system, Int. J. of Heat and Mass Transfer, Vol. 39 (1996), pp.527-536.

(11) Takeda, T. and Hishida, M, Studies on diffusion and natural convection of two-component gases, Nuclear Engineering and Design, Vol.135 (1992), pp.341-354.

(12) Patankar, S. V., Numerical Heat Transfer and Fluid Flow, (1980), McGraw-Hill.

(13) Spalding, D. B., A novel finite-difference formulation for differential expressions involving both first and second derivatives, Int. J. Num. Methods Eng., Vol. 4 (1972), p.551.

(14) Kunitomi, K., et al., Depressurization accident analysis for the HTTR by the TAC-NC, Energy, Vol. 16 (1991), pp.471-480.

(15) Kunitomi, K., et al., Thermal transient analyses during a depressurization accident in the HTTR, JAERI-M, 91-163 (1991), in Japanese. 